\title{
The Impact of Train Staff on the Customer Experience
}

\author{
Mark van Hagen and Jessica Sauren \\ Research and Development Department, Netherlands Railways, Utrecht 3500HA, the Netherlands
}

\begin{abstract}
The NS (Netherlands Railways) has developed an instrument which allows the measurement of both hard and less tangible quality aspects. This instrument, the so-called TEM (train experience monitor), monitors the quality experiences of customers with an aim to influencing key areas and underlying aspects. The TEM is a measurement instrument based on scientific evidence and questions passengers on the most important aspects of the train and train journey. These can be either functional questions on, e.g., security, cleanliness and information provision, or more emotional questions on the atmosphere and comfort of the train, e.g., whether passengers find the train pleasant and they feel welcome, including the role of the staff. The experience of a train journey can be influenced in three dimensions: process, people and place. Our focus in this study is on the importance of the people dimension, and for this purpose, the train staff experimented with a number of scripts which varied in their approach to tannoy announcements, ticket control and service provision. The findings show that the script focusing on control in combination with a warm (instead of a rational/business-like) service provision generates the highest assessment of the staff. On scrutinizing the influence of the scripts on the general assessment of the train journey, it is quite clear that the aforementioned script has a significant and positive impact.
\end{abstract}

Key words: Train, staff, experience, measure, general assessment.

\section{Introduction}

Many studies on service provision have been carried out in the last 30 years. According to Chase and Dasu [1], surprisingly, little time has been devoted to researching services from the customer's point of view. Pine and Gilmore [2] found that the service economy is turning into an experience economy, in which there is a growing awareness of the way in which experience affects consumer behavior. For more and more services, the argument is that not only should a good service be provided on a utilitarian level, but that it should also include the component of hedonic experiential value. Experiential value will always be created somewhere, sometime. Pine and Gilmore [2] compared a service to the theatre, in which the service environment is the stage, the staff are the actors and the customers are the audience. In the case of railways, the station can be seen as the stage set, with the staff as the actors. The set must serve the performance and the actors must know their roles. Employees need to know what

Corresponding author: Mark van Hagen, Dr., research fields: transport and behavioral sciences. E-mail: mark.vanhagen@ns.nl. responsibilities they have in order to contribute to the overall experience. This paper describes the results of an experiment in which staff match their communication and behavior as closely as possible to what passengers want.

\subsection{Quality Dimensions of a Train Journey}

It is important to appreciate that a journey by public transport is not a product but a service. The fundamental difference between a product and a service is that a service is produced and consumed at the same time. Therefore, the consumer is "in the factory" and experiences the service within the physical facilities of the service environment. The experience of a service can be controlled in three dimensions [3, 4], which are interrelated:

- process: the service processes (e.g., timetables and information);

- people: the people present (staff and customers);

- place: the service environment (e.g., design, colors and materials).

Processes are strongly related to time and the efficiency is key: the more efficient and smoother the 
service, the more satisfied customers will be. In the case of a journey by public transport, time is of the essence. For example, passengers must be on time to catch their train.

The presence of adequate and competent staff influences customer satisfaction in a positive sense, and a public transport journey is no exception. As well as staff, the presence of other people in the service environment influences the perception of the service: too many or too few customers in the service environment can lead to negative feelings. For example, a deserted or overcrowded train can provoke negative emotions and avoidance behavior.

Finally, the service environment has a strong influence on the perception of the satisfaction of the service. Because a service is not tangible, customers will often unconsciously look for things in the service environment that say something about the quality to be expected. If the environment is safe, clean and suitable for the service offered, the consumer will have greater confidence in the quality of the service-provider. In public transport, too, passengers look for quality signals on the station and in the vehicle. Fig. 1 schematically illustrates the three quality dimensions of a service and their interdependence. It can be seen that processes form the base of the pyramid of customer needs $[5,6]$, these are the dissatisfiers, while the service environment (place) and staff (people) are primarily satisfiers. If we carry out excellent processes, we get satisfied passengers, but no more than that (they do not complain). Only by offering a perfect service environment with staff who are passionate about what they do, will we get happy passengers. Staff not only provide information or ensure safety (base of pyramid), but they can also identify with customers' wishes (top of pyramid) and interact with customers in a friendly way, for example.

\subsection{How Does Behavior Arise?}

The service evokes emotional reactions that influence people's behavior (Fig. 2). This behavior is influenced unconsciously for the most part (95\%). Avoidance behavior is all the negative behavior that is evoked, such as wanting to leave, not wanting to explore the place, not feeling any rapport with the place and not wanting to come back. An environment where people feel uncomfortable, such as an unpleasant, noisy and disorderly place, is one that people want to avoid.

Approach behavior refers to the positive behavior that is generated by the service, such as wanting to remain in the place, wanting to explore the place, feeling a rapport with the place and wanting to come back. Approach behavior can be stimulated through a

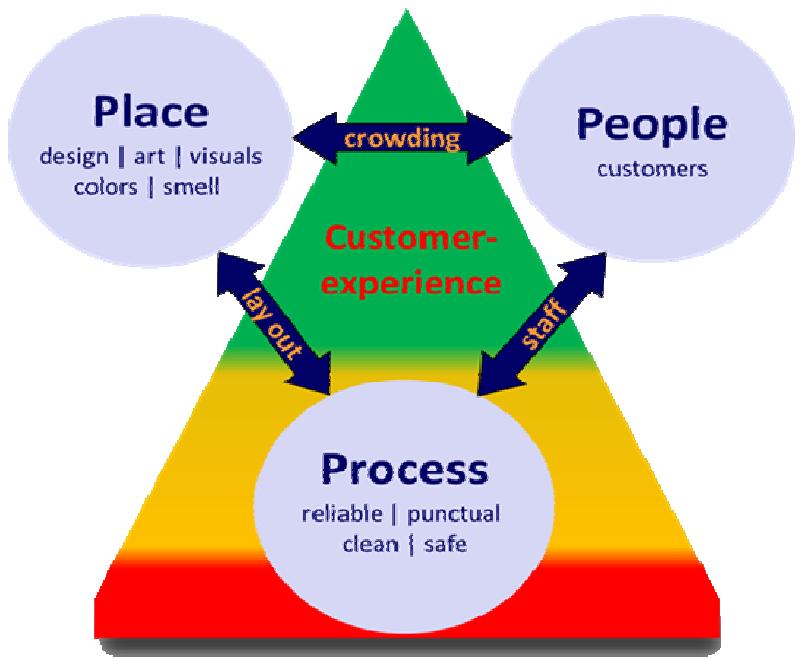

Fig. 1 Interrelationship of the three quality aspects of a train service.

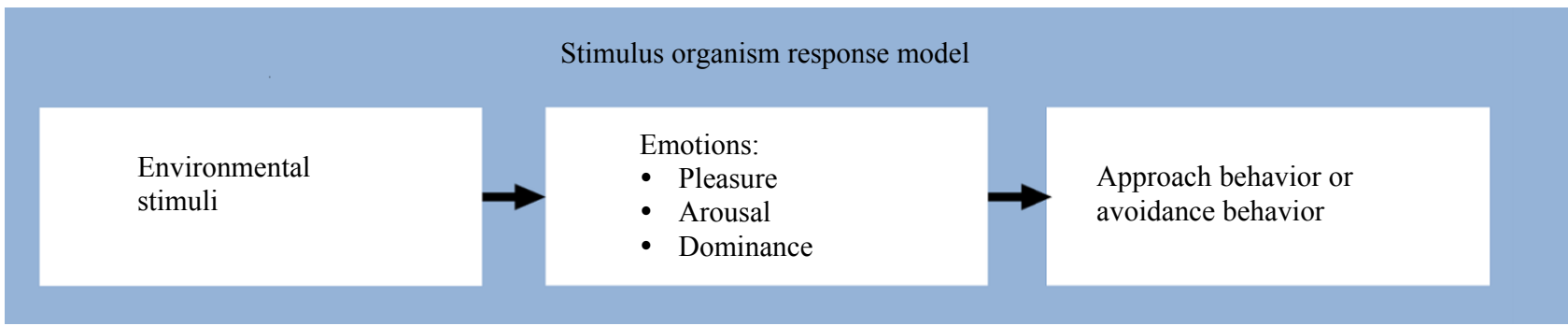

Fig. 2 Stimulus organism and response model $[7,8]$. 
deliberate choice of design and by adding the right (in)tangible stimuli to the environment. The key to changing passenger behavior therefore lies in influencing the emotions of our passengers. Emotions are influenced above all by the attitude and behavior of staff and by the quality of the train service environment.

\subsection{Research Questions and Hypotheses}

This paper describes a study in which aspects of the work of the conductor are manipulated. The study involved performing six "scripts" being distinguished. There were three main scripts, each with a warm version and a factual version. The factual version only provides functional information such as the departure time and a message indicating which stations the train stops at. The warm announcement also provides this information, but first welcomes passengers on behalf of the whole team and adds more service-oriented information, such as mentioning the availability of Wi-Fi on board the train and a quiet compartment where passengers are asked to respect the peaceful atmosphere.

The aim of the study is to see whether differences in customer perception can be identified between the different scripts and which scripts are rated most positively by passengers.

The survey questions relating to the passenger experience are as follows:

- What does the passenger think about the staff?

- What does the passenger think about the train and the train journey?

The hypotheses are formulated as follows:

- Hypothesis I: The visibility of the conductor is rated higher than mere contact via announcements;

- Hypothesis II: A script with a warm approach is rated more positive by passengers than scripts with a factual approach;

- Hypothesis III: The most highly appreciated scripts are those in which a service round is combined with a ticket inspection.

\subsection{Scripts}

Six different scripts were used: three main scripts, each with a warm version and a factual version.

- Script 1: announcement only (audible, not visible ("I'm here")). After departure, the conductor makes an announcement and does not show himself to passengers. A distinction is made between the following versions: (a) factual, short announcement; (b) warm, service-oriented announcement;

- Script 2: ticket inspection and service (audible and visible ("I'm here for you, provide service and inspect tickets")). After departure, the conductor makes an announcement. He/she then does a service-oriented inspection round, actively making personal contact with passengers. A distinction is made between the following versions: (a) factual and brief announcement/attitude; (b) warm and service-oriented announcement/attitude;

- Script 3: service (personal contact ("I'm here for you and provide service")). After departure, the conductor makes an announcement. He/she then does a round through the train, actively making personal contact with passengers, but does not perform an inspection. A distinction is made between the following versions: (a) factual and brief announcement/attitude; (b) warm and service-oriented announcement/attitude.

\section{Method}

\subsection{Subjects}

A total of 5,026 (usable) questionnaires were distributed for this study. Of the 5,026 passengers who participated in the study, $46.9 \%$ were male and $53.1 \%$ female. The average age was 37 years ( $S D$ (standard deviation $)=17.3$ ). Table 1 shows the number of respondents per script.

\subsection{Design and Procedure}

Sixteen conductors took part in the study on a 
voluntary basis. They received two days' training led by a supervisor, the researchers and an actor to practice the scripts. This training was important to familiarize the conductors with the different scripts, so that each script could be performed clearly and the conductors felt comfortable with it. To give the scripts an authentic feeling and match them to the character of each conductor, the scripts were not written out word for word, but the core and structure of the text and mode of behavior were the same for each conductor.

Research was carried out among passengers to test the effect of the measures (scripts) used in the experiment. This involved a questionnaire supplied by TEM (Train experience monitor) [6]. A few extra questions concerning the staff were added to this standard questionnaire to find out what customers think of them.

The survey was carried out on 17 measurement days between March 12 and April 20, 2013. The experiment was carried out exclusively on intercity trains. The study was conducted on different routes across the country, both on weekdays and at weekends, during peak and off-peak periods.

\subsection{Measurements}

The variables are measured on a 10-point scale where 1 means "strongly disagree" and 10 means "strongly agree" or (depending on the question) "very poor" and "excellent", respectively. The questionnaire includes items that focus on dissatisfiers and satisfiers within the following themes: speed, staff, atmosphere, comfort, safety and cleanliness, plus a number of general opinions. Opinions regarding staff are measured with questions such as "During this train journey, I think the NS (Netherlands Railways) staff are ... visible/friendly/professional, etc.”.

\section{Results and Discussions}

The main question is which of the scripts performed by the conductors is most appreciated by passengers. To answer this question, all six scripts are compared with one another. The scripts are compared with one another in different ways based on the variable of general opinion of staff: firstly, all six scripts with one another (Script 1a vs. Script $1 \mathrm{~b}$ vs. Script 2a vs. Script $2 b$ vs. Script 3a vs. Script 3b); secondly, all factual scripts versus all warm scripts (a vs. b); and thirdly, the "announcement only" scripts versus the "service and inspection" scripts versus the "service" scripts (Script 1 vs. Script 2 vs. Script 3).

\subsection{Comparison of Six Scripts}

From the comparison of the six scripts (Tables 2 and 3 and Fig. 3), it appears that the scripts differ significantly from one another and that staff are rated most positively in Scripts $2 b$ (service and inspection (warm)) and $3 b$ (service (warm)).

We also find significant differences between warm and factual scripts, in which the warm scripts are viewed more and more positively by passengers than the factual scripts. Even when the conductor only uses

Table 1 Number of respondents per script.

\begin{tabular}{lc}
\hline Script & Number of respondents \\
\hline Script 1a & 859 \\
Script 1b & 773 \\
Script 2a & 1,002 \\
Script 2b & 1,023 \\
Script 3a & 706 \\
Script 3b & 663 \\
\hline Total & 5,026 \\
\hline
\end{tabular}

Table 2 Average general opinion of staff per script.

\begin{tabular}{llll}
\hline Script & $N$ & $\begin{array}{l}\text { Average general opinion of } \\
\text { staff }\end{array}$ & $S D$ \\
\hline $1 \mathrm{a}$ & 542 & 6.82 & 1.73 \\
$1 \mathrm{~b}$ & 553 & 7.18 & 1.41 \\
$2 \mathrm{a}$ & 933 & 7.38 & 1.21 \\
$2 \mathrm{~b}$ & 956 & 7.78 & 1.21 \\
$3 \mathrm{a}$ & 530 & 7.19 & 1.33 \\
$3 \mathrm{~b}$ & 609 & 7.62 & 1.20 \\
\hline
\end{tabular}

Table $3 d f$ (degrees of freedom), $F$ - statistic and ANOVA (analysis of variance) significance value comparing six scripts.

\begin{tabular}{lll}
\hline$d f$ & $F$ value & $p$ \\
\hline 5,4117 & 45.07 & 0.000 \\
\hline
\end{tabular}


What is your general opinion of the staff on this train?

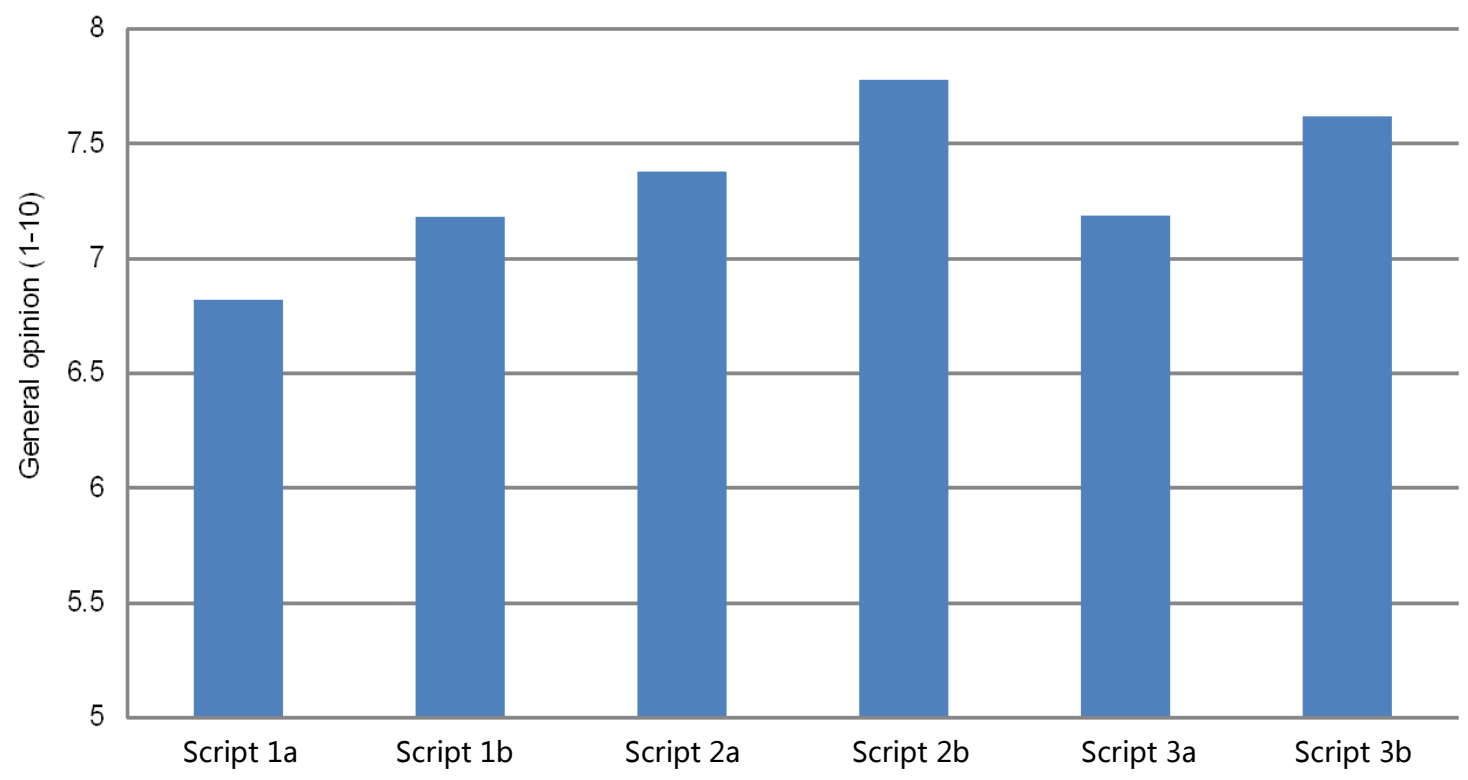

Fig. 3 Average general opinion of staff per script.

the announcement, a warm announcement is rated more highly than a factual announcement. However, the physical presence of staff scores better than the announcement. It appears that passengers appreciate it if they not only hear the train staff, but also see them.

To determine which scripts differ significantly from one another, a post-hoc test (Bonferroni) was performed. These results can be found in Appendix A. We find that there are significant differences between the factual and warm scripts and between the announcement on its own and the combination of announcement with inspection or service round. The results remain the same when we control for weekday/weekend, peak/off-peak, delay/no delay. We consider which scripts are viewed more positively in the following.

\subsection{Comparison of Factual and Warm Scripts}

Looking at factual versus warm scripts, we find that the staff receive a (significantly) higher score from passengers in the case of a warm script rather than a factual script (Tables 4 and 5 and Fig. 4).
3.3 Comparison of Announcement Only, and Service and Inspection, and Service

We also compare the averages of the three main variants: "announcement only", "service and inspection", and "service". The results indicate that all three scripts differ (significantly) from one another: passengers' general opinion of staff is the highest when the "service and inspection" script is used, followed by the "service" script and finally the "announcement only" script (Tables 6 and 7 and Fig. 5).

To determine which scripts differ significantly from one another, a post-hoc test (Bonferroni) was performed. These results are shown in Table 8 . It appears that all the scripts differ significantly from one

Table 4 Average general opinion of staff, factual/warm.

\begin{tabular}{llll}
\hline Script & $N$ & $\begin{array}{l}\text { Average general opinions } \\
\text { of staff }\end{array}$ & $S D$ \\
\hline Factual & 2,005 & 7.2 & 1.42 \\
Warm & 2,118 & 7.6 & 1.29 \\
\hline
\end{tabular}

Table $5 d f, F$ value and ANOVA significance value, factual/warm.

\begin{tabular}{lll}
\hline$d f$ & $F$ value & $p$ \\
\hline 1,4121 & 89.94 & 0.000 \\
\hline
\end{tabular}




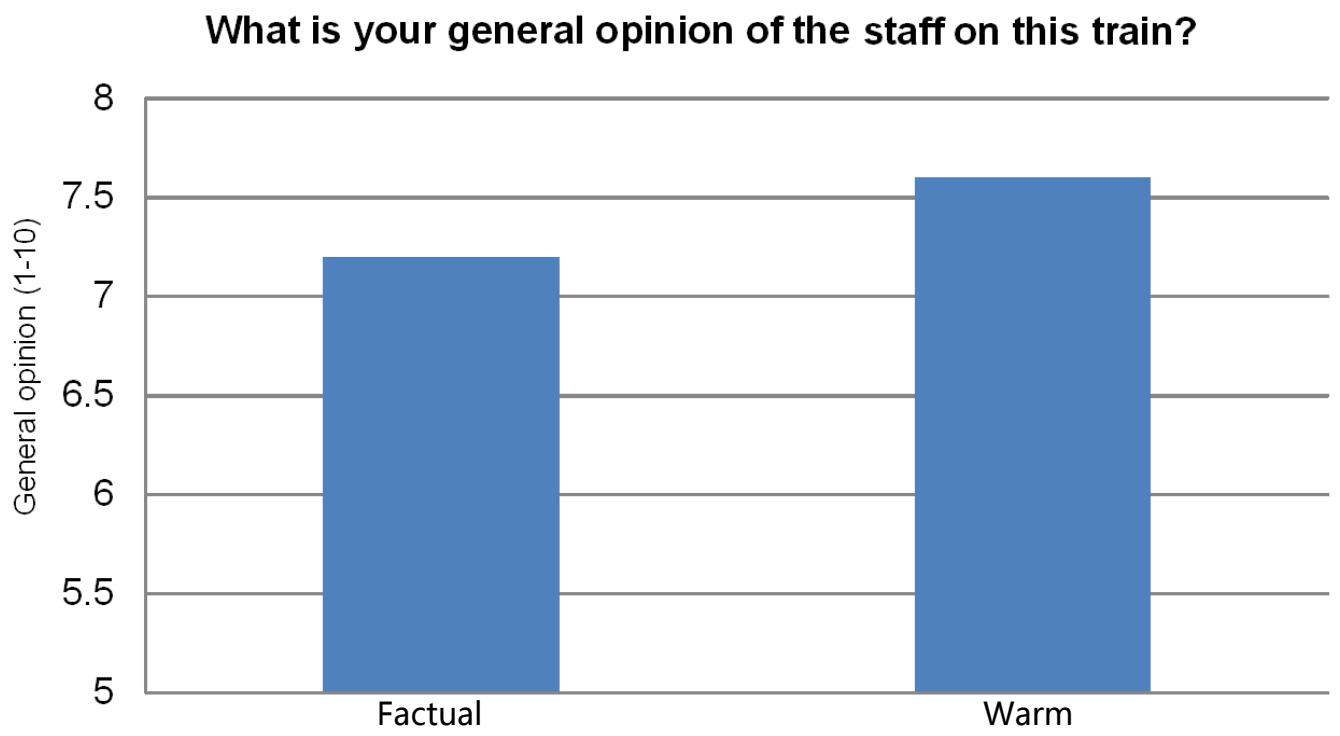

Fig. 4 Average general opinion of staff, factual vs. warm.

Table 6 Average general opinion of staff: announcement, service and announcement, and service.

\begin{tabular}{llll}
\hline Script & $N$ & $\begin{array}{l}\text { Average general } \\
\text { opinions of staff }\end{array}$ & $S D$ \\
\hline Announcement only & 1,095 & 7.0 & 1.59 \\
Service and & 1,889 & 7.6 & 1.23 \\
announcement & 1,139 & 7.4 & 1.28 \\
Service &
\end{tabular}

Table $7 d f, F$ value and ANOVA significance value, announcement, service and announcement, and service.

\begin{tabular}{lll}
\hline$d f$ & $F$ value & $p$ \\
\hline 2,4120 & 64.97 & 0.000 \\
\hline
\end{tabular}

another. Customers even notice a difference between a service round on its own and a service round combined with a ticket inspection. As we saw earlier (Fig.3), the service round combined with inspection is rated the highest. It appears that passengers not only require service, but also like it when the conductor inspects their ticket, which after all they have paid for. Without an inspection, passengers may have the feeling of not being taken seriously and that they have paid "for nothing".

\subsection{Regression of Opinion of Train Journey}

What is the contribution of staff to the general opinion of the train journey? If we look at the importance of each script separately (Table 5), it is clear that the contribution to the general opinion of the train journey is the greatest in the case of Scripts 2a (service and inspection (factual)) and $2 b$ (service and inspection (warm)): both account for $30 \%$ of the general opinion of the train journey. Fig. 6 shows the contribution of each theme in the case of Script $2 b$. For comparison, Fig. 3 shows the contribution of staff in the normal situation, without the use of scripts. The contribution of staff remains at $15 \%$.

It is noticeable that the increased contribution in the case of Script $2 b$, for example, is at the expense of the effect that the timetable has on the general opinion of train the journey.

\subsection{Feedback on Hypotheses}

The formulated hypotheses were as follows:

- Hypothesis I: Visibility of the conductor is rated higher than just contact via announcement. This hypothesis is confirmed. Scripts $1 \mathrm{a}$ and $1 \mathrm{~b}$ (where the conductor only has contact with passengers via announcements) are rated significantly lower than the other scripts (where the conductor is visible). From the comparison of the scripts "announcement only" (Scripts 1a and 1b), "service and inspection" (Scripts $2 a$ and 2b) and "service" (Scripts 3a and 3b), it appears that Scripts $1 \mathrm{a}$ and $1 \mathrm{~b}$ are rated significantly lower than Scripts $2 a$ and $2 b$ and $3 a$ and $3 b$ (Fig. 3). 


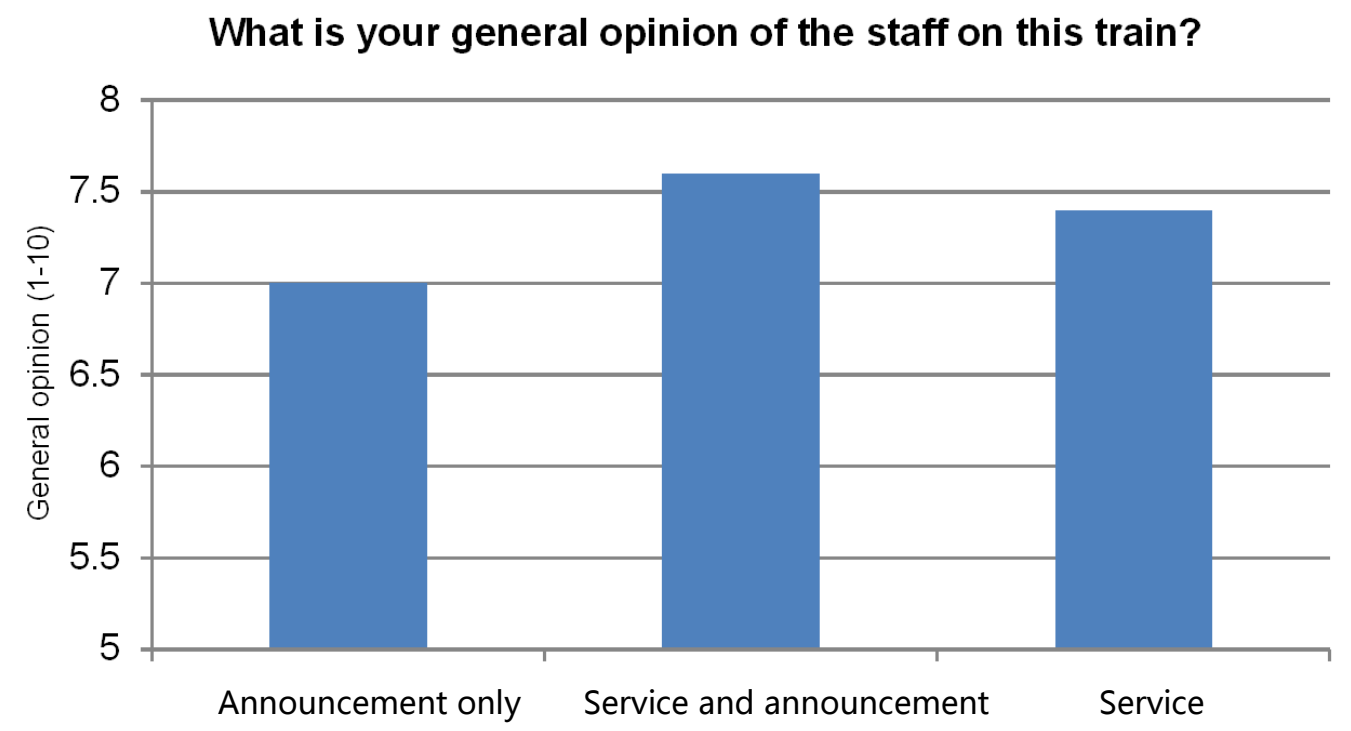

Fig. 5 Average general opinion of staff: announcement only vs. service and inspection vs. service.

Table 8 Post-hoc test (Bonferroni), comparison of announcement only vs. service and inspection vs. service.

\begin{tabular}{lll}
\hline Script & Compared with & $p$ \\
\hline \multirow{2}{*}{ Announcement only } & Service and inspection & 0.000 \\
& Service & 0.000 \\
Service and inspection & Announcement only & 0.000 \\
& Service & 0.005 \\
Service & Announcement only & 0.000 \\
& Service and inspection & 0.005 \\
\hline
\end{tabular}

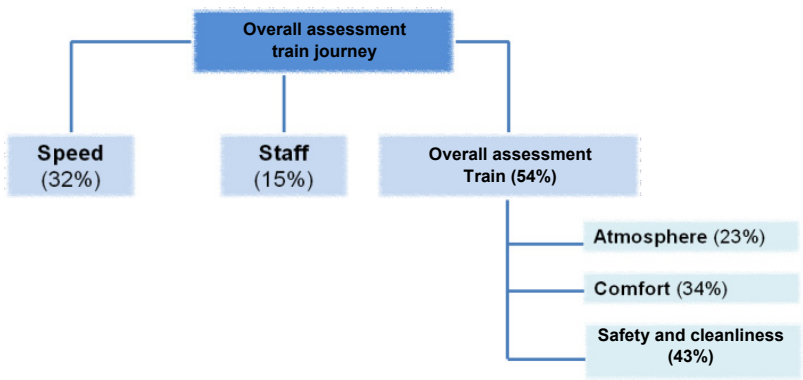

(a)

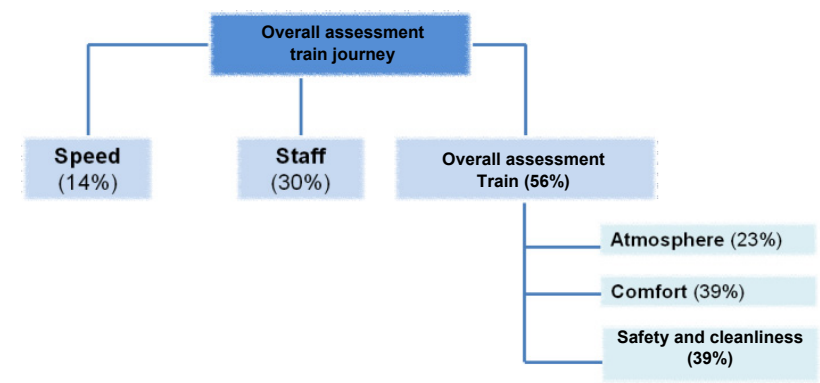

(b)

Fig. 6 Contribution to general opinion of train journey: (a) in a normal situation; (2) where Script $2 b$ is used.
- Hypothesis II: Scripts with a warm approach are rated more positive by passengers than scripts with a factual approach. This hypothesis is confirmed. Scripts with a warm approach are consistently rated higher than factual scripts (Fig. 3). This is true for each variant (announcement, inspection, service and inspection) and in all circumstances (peak and off-peak, weekday and weekend, without delay and with delay);

- Hypothesis III: The most highly appreciated scripts are those in which a service round is combined with a ticket inspection. This hypothesis is confirmed. Passengers appreciate a service-oriented inspection round most of all (Fig. 3). The greatest difference is that between an announcement on its own and the conductor's physical presence in the train, he is also visible to the customer. The difference between a warm service round and a warm service round with inspection is not so great. Passengers appreciate a warm service round (where they are not asked for their tickets) even more than a factual inspection round.

\section{Conclusions}

\subsection{Summary of Findings}

From the experiment with different scripts (warm and factual), it appears that, in all circumstances, warm, 
service-oriented scripts are rated (peak/off-peak, weekday/weekend, delay/no delay) more positively than factual scripts, in which only functional messages are given. The differences between scripts can amount to a whole point (Script 1a scores 6.8 compared with 7.8 for Script $2 b$ in Table 2).

Use of the warm scripts increases the relative importance of the role of the staff in the overall service-provision. The staff's contribution to the general opinion of the train journey increases from $15 \%$ in a normal situation (without scripts) to $30 \%$ in a situation where the warm scripts are used with inspection (Fig. 6). It is noticeable that this is at the expense of the basic service (performance of the operating schedule) and not of the role of the service environment (Figs. 1 and 6).

\subsection{Practical Implications}

The results show that, in all circumstances, warm and service-oriented scripts lead to a more positive travel experience than the more functional scripts. Because the staff have experience with different scripts, they can use different scripts according to the situation, though the warm scripts are always preferred to the factual scripts. For example, if the train is (unexpectedly) very busy and it is almost impossible to walk through the train, the conductor can still provide service by making announcements in a service-oriented way, e.g., welcoming everybody, apologizing for the (unexpected) crowding on the train and asking people to show consideration for each other by placing luggage in the baggage areas and not on the seats.
When things are very quiet, the conductor can walk through the train easily and has more time to make personal contact with passengers. In this case, the warm service-oriented scripts are highly suitable, whether or not combined with an inspection. Such use of scripts depending on the situation improves the general opinion of the train journey, and staff come to play a more important role in the overall service provided to the passenger. And as Pine and Gilmore [2] have previously said, "when the actors know their role, the overall performance is undoubtedly better".

\section{References}

[1] Chase, R. B., and Dasu, M. 2001. "Want to Perfect Your Company's Service? Use Behavioral Science." Harvard Business Review 6: 78-84.

[2] Pine, B. J., and Gilmore, J. H. 1999. The Experience Economy. Work Is Theatre \& Every Business a Stage. Boston: Harvard Business School Press.

[3] Bitner, M. J. 1992. "Servicescapes: The Impact of Physical Surroundings on Customers and Employees." Journal of Marketing 56 (4): 57-71.

[4] Zeithaml, V. A., and Bitner, M. J. 2003. Services Marketing. Integrating Customer Focus across the Firm. 3rd ed.. New York: McGraw-Hill Higher Education.

[5] Van Hagen, M. 2011. "Waiting Experience at Train Stations." Dissertation, Eburon.

[6] Van Hagen, M., and Sauren, J. 2014. "Influencing the Train Experience: Using a Successful Measurement Instrument." Presented at ETC (European Transport Conference 2013, Germany.

[7] Mehrabian, A., and Russell, J. A. 1974. An Approach to Environmental Psychology. USA: MIT (Massachusetts Institute of Technology) Press.

[8] Russell, J. A., and Mehrabian, A. 1977. "Evidence for a Three-Factor Theory of Emotions." Journal of Research in Personality 11 (3): 273-94.

\section{Appendix A}

Table A1 Post-hoc test (Bonferroni), comparison of six scripts.

\begin{tabular}{lll}
\hline Script & Compared with & $p$ \\
\hline \multirow{4}{*}{$1 \mathrm{a}$} & $1 \mathrm{~b}$ & 0.000 \\
& $2 \mathrm{a}$ & 0.000 \\
& $2 \mathrm{~b}$ & 0.000 \\
& $3 \mathrm{a}$ & 0.000 \\
& $3 \mathrm{~b}$ & 0.000 \\
\hline
\end{tabular}


(Table A1 continued)

\begin{tabular}{|c|c|c|}
\hline Script & Compared with & $p$ \\
\hline \multirow{5}{*}{$1 \mathrm{~b}$} & $1 \mathrm{a}$ & 0.000 \\
\hline & $2 \mathrm{a}$ & 0.071 \\
\hline & $2 b$ & 0.000 \\
\hline & За & 1.00 \\
\hline & $3 \mathrm{~b}$ & 0.000 \\
\hline \multirow{5}{*}{$2 a$} & $1 \mathrm{a}$ & 0.000 \\
\hline & $1 \mathrm{~b}$ & 0.071 \\
\hline & $2 b$ & 0.000 \\
\hline & 3a & 0.128 \\
\hline & $3 b$ & 0.006 \\
\hline \multirow{5}{*}{$2 b$} & $1 \mathrm{a}$ & 0.000 \\
\hline & $1 \mathrm{~b}$ & 0.000 \\
\hline & $2 \mathrm{a}$ & 0.000 \\
\hline & За & 0.000 \\
\hline & $3 b$ & 0.397 \\
\hline \multirow{5}{*}{ 3a } & $1 \mathrm{a}$ & 0.000 \\
\hline & $1 \mathrm{~b}$ & 1.00 \\
\hline & $2 \mathrm{a}$ & 0.128 \\
\hline & $2 b$ & 0.000 \\
\hline & $3 b$ & 0.000 \\
\hline \multirow{5}{*}{$3 b$} & 1a & 0.000 \\
\hline & $1 \mathrm{~b}$ & 0.000 \\
\hline & $2 a$ & 0.006 \\
\hline & $2 b$ & 0.397 \\
\hline & За & 0.000 \\
\hline
\end{tabular}

